\title{
Verifikasi Tanda Tangan Dengan Edge Detection Dan Metode Learning Vector Quantization
}

\author{
Irma Amelia ${ }^{(1)}$, Asep Nana Hermana ${ }^{(1)}$, Andri Pramana ${ }^{(1)}$ \\ (1) Jurusan Teknik Informatika, Fakultas Teknologi Industri \\ Institut Teknologi Nasional Bandung \\ Email: imameamel@gmail.com
}

\begin{abstract}
ABSTRAK
Tanda tangan merupakan salah satu karakteristik yang dimiliki oleh setiap orang . Kasus pemalsuan tanda tangan cukup banyak terjadi ${ }^{[6]}$. Hal ini dikarenakan kurangnya sistem verifikasi dalam pengidentifikasian tanda tangan. Berdasarkan hal tersebut, dibangun aplikasi verifikasi tanda tangan. Aplikasi yang dibangun menggunakan metode edge detection dalam pengekstraksi ciri dan metode jaringan syaraf tiruan Learning Vector Quantization ( $L V Q)$ pada pencocokan pola tanda tangan. Aplikasi verifikasi tanda tangan diawali dengan pemindaian tanda tangan lalu diekstraksi ciri dan disimpan ke dalam basisdata yang digunakan sebagai data latih. Kemudian pengguna memindai tanda tangan uji dan sistem mencocokan dengan data latih menggunakan metode LVQ. Hasil pencocokan dari aplikasi tersebut didapat persentase sebesar $70 \%$ tanda tangan asli yang terverifikasi dengan benar dan Tingkat kesalahan dalam system verifikasi tanda tangan dalam membaca tanda tangan palsu sebesar 30\% sistem membaca dengan tanda tangan asli. Aplikasi ini dapat memverifikasi tanda tangan.
\end{abstract}

Kata kunci : Tanda tangan, Verifikasi. Edge detection, LVQ, Jaringan syaraf tiruan

\begin{abstract}
The signature is one of the characteristics possessed by each person. Many signature forgery case. This is because the lack of a verification system in identifying signature. Based on this, signature verification applications are built. Applications built using edge detection methods in extracting the characteristics and methods of neural network Learning Vector Quantization (LVQ) the signature pattern matching. Applications signature verification begins by scanning the signature traits extracted and stored in a basis data that is used as training data. Then users scan signatures match the system test and training data using LVQ. Matching results obtained from the application of the percentage of $70 \%$ original signatures are verified correctly and the error rate in the signature verification system in reading the signature of $30 \%$ false reading system with the original signature. This application can verify the signature.
\end{abstract}

Keywords: Signature, Verification. Edge detection, LVQ, neural network. 


\section{PENDAhULUAN}

Tanda tangan merupakan salah satu karakteristik yang dimiliki oleh setiap orang. Seringnya terjadi pemalsuan tandatangan, antara lain disebabkan oleh sistem verifikasi yang kurang baik. Verifikasi tandatangan kebanyakan dilakukan dengan cara manual, yaitu dengan membandingkan secara langsung dengan menggunakan mata manusia yang mempunyai banyak kelemahan pengelihatan seseorang menjadi letih, terutama jika melakukan cukup banyak verifikasi, dapat menyebabkan kebosanan orang yang melakukannya, sehingga ketelitian dan ketepatan hasil yang diinginkan seringkali kurang memuaskan.

Pengenalan dan verifikasi tanda tangan meliputi dua bagian yang berbeda tetapi berkaitan erat satu sama lain. Yang pertama adalah identifikasi dari pemilik tanda tangan, sedangkan yang kedua adalah keputusan apakah tanda tangan tersebut asli atau dipalsukan. Selain itu, bergantung pada kebutuhannya, pengenalan tanda tangan dibagi menjadi dua kelas yang berbeda yaitu pengenalan dan verifikasi tanda tangan online dan offline.

Metode verifikasi tanda tangan dari berbagai penelitian yang berkembang saat ini tidak banyak yang menggunakan metode yang berbasis sinyal pada tahap ekstraksi ciri. Edge detection bisa dijadikan penelitian untuk mengenali ciri karakteristik dari tanda tangan secara offline. Deteksi tepi berfungsi untuk mengidentifikasikan garis batas dari suatu objek terhadap latar belakang yang saling tumpang tindih. Sehingga apabila garis tepi pada citra dapat diidentifikasikan dengan akurat, semua objek dapat ditemukan dan sifat dasar seperti area, bentuk, dan ukuran objek dapat diukur

Dalam proses verifikasi tanda tangan, proses klasifikasi sama pentingnya dengan proses ekstraksi fitur. Setelah fitur-fitur penting data atau sinyal yang dihasilkan pada proses ekstraksi fitur, fitur-fitur tersebut nantinya akan digunakan untuk proses klasifikasi. Metode klasifikasi yang digunakan adalah pengklasifikasi LVQ (Learning Vector Quantization) adalah suatu metode klasifikasi pola yang masing-masing unit keluaran mewakili kategori atau kelas tertentu. Suatu lapisan kompetitif akan secara otomatis belajar untuk mengklasifikasikan vektor - vektor masukan. Pada penelitian ini, dibagun aplikasi verifikasi tanda tangan untuk menguji keaslian dari sebuah tanda tangan. Dengan menggabungan Edge Detection sebagai ekstraksi fitur dan metode LVQ (Learning Vector Quantization) sebagai pengklasifikasiannya. Penelitian dilakukan dengan batasan pengambilan citra tanda tangan secara offline, penulisan tanda tangan harus diatas kertas putih polos, penulisan menggunakan pulpen warna hitam.dan gambar di ambil dengan scanner. Hal ini dilakukan agar memperoleh hasil pengujian terhadap penelitian yang optimal.

\section{METODOLOGI PENELITIAN}

Metode penelitian dibagi menjadi dua tahap yaitu metode metode pengembangan aplikasi dan pengumpuluan data.

\subsection{Metode Pengembangan Aplikasi}

Pada penelitian ini pengembangan aplikasi dilakukan menggunakan metode Waterfall. Pada tahap awal persiapan dan perencanaan dilakukan proses pengambilan data tanda tangan yang akan diproses sebagai data latih. Kemudian selanjutnya dilakukan tahap analisis terhadap metode ekstrasi ciri menggunakan metode deteksi tepi operator Prewitt, dilanjutkan dengan tahap perancangan basis data dan desain antarmuka.Selanjutnya tahap pengkodean dilakukan menggunakan MATLAB mengimplementasikan metode deteksi tepi operator Prewitt dan LVQ untuk pencocokan data latih dan data uji. Implementasi dari segi desain antarmuka juga dilakukan. Pengujian sistem dilakukan terhadap 10 pengguna dengan masing-masing 10 tanda tangan.

\subsection{Metode Pengumpulan Data}

\section{Studi literature}

Diawal penelitian dilakukan terlebih dahulu pemahaman materi terhadap metode dan penelitian sebelumnya melalui beberapa tinjauan literature. 
2. Pengumpulan data primer

Pada penelitian ini dilakukan pengumpulan data primer dengan cara mengumpulkan sampel data tanda tangan dari teman-teman mahasiswa.

Pada tahap ini melakukan pengumpulan data tanda tangan untuk dijadikan data latih penelitian. Masing-masing tanda tangan setiap pengguna sejumlah 30 tanda tangan sebagai data latih.

\section{ANALISIS DAN PEMBAHASAN}

Pada penelitian ini dilakukan tahapan-tahapan untuk dapat melakukan identifikasi tanda tangan seseorang.

\subsection{Analisi Sistem}

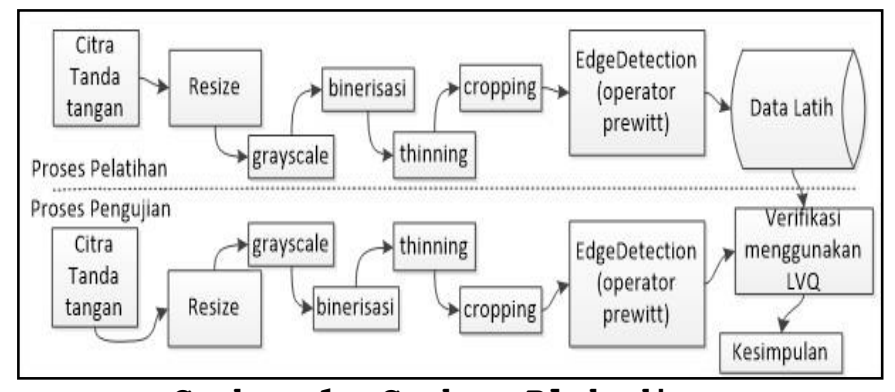

Gambar 1. Gambar Blok diagram

Tahapannya dibagi menjadi 2 proses yaitu, proses pelatihan dimana sistem akan mendata contoh-contoh tanda tangan yang menjadi acuan saat proses identifikasi. Berikutnya adalah proses pengujian dimana sistem melakukan proses identifikasi dari tanda tangan pengguna yang disesuaikan dengan tanda tangan yang sudah tersimpan di basisdata. Proses pelatihan dilakukan dengan beberapa tahap diantaranya:

\section{Mendata citra tanda tangan}

Citra tanda tangan sebagai masukan dari langkah awal dari kerja sistem. Citra tanda tangan yang berupa citra digital.

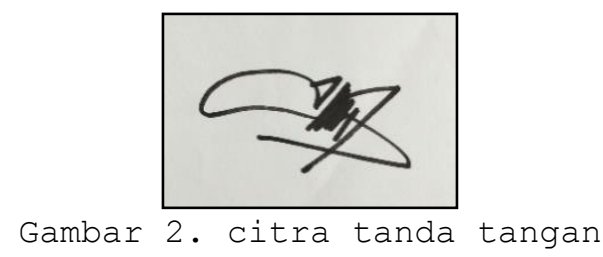

\section{Tahap Resize}

Pada tahap resize ukuran gambar akan diubah sesuai ukuran yg ditentukan. Di tentukan dengan ukuran citra 100x100pixel. agar semua gambar yang diuji seragam ukurannya sehingga menghasilkan keluaran yg sesuai. pada proses resize menggunakan MATLAB. MATLAB menyediakan fungsi untuk melakukan proses Resize yaitu imresize. Contoh resize gambar ke 100x100 pada MATLAB.

$\mathrm{I} 2=$ imresize $(\mathrm{I},[100,100])$;

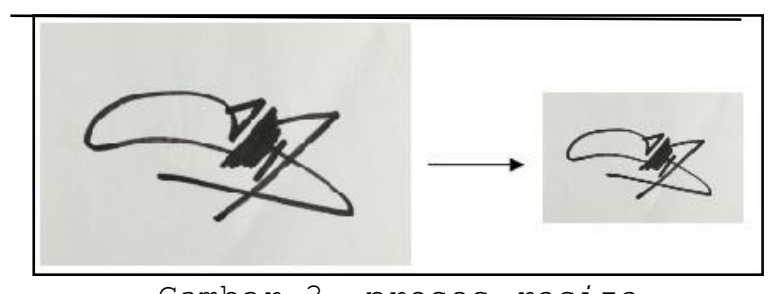

3. Tahap Grayscale

Gambar 3. proses resize

Tahap prapemrosesan bertujuan untuk memperbaiki citra dengan cara memanipulasi parameter citra agar menjadi citra dengan kualitas yang lebih baik. Dalam penelitian ini, prapemrosesan terdiri dari konversi RGB ke grayscale. Rumus untuk proses grayscale: 
$\mathrm{I}(\mathrm{x}, \mathrm{y})=\alpha^{*} \mathrm{R}+\beta^{*} \mathrm{G}+\gamma^{*} \mathrm{~B} \ldots .$.

Keterangan :

$I(\mathrm{x}, \mathrm{y})=$ level keabuan pada suatu koordinat

$\mathrm{R}=$ nilai warna merah

$\mathrm{G}=$ nilai warna hijau

$\mathrm{B}=$ nilai warna biru

Dengan konstanta nilai $\alpha=0.2989, \beta=0.5870, \gamma=0.1140$

MATLAB menyediakan fungsi untuk melakukan proses grayscale dengan coding rgb2gray. Pada penerapannya dengan cara $\mathrm{I} 3=\operatorname{rgb} 2 \operatorname{gray}(\mathrm{I} 2)$;

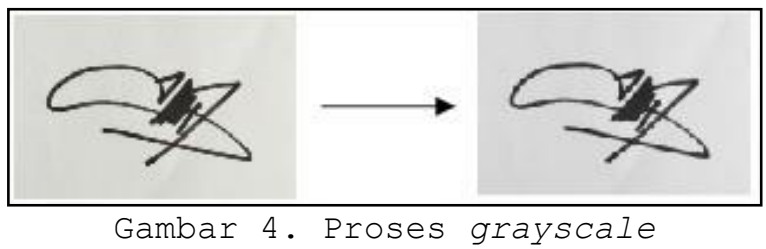

\section{Tahap Binerisasi}

Proses binerisasi melibatkan pengujian nilai tingkat keabu-abuan dari tiap piksel yang dinilai nilai biner satu, warna dari hasil proses biner akan menjadi 2 warna saja, yaitu warna hitam dan warna putih. MATLAB menyediakan fungsi untuk melakukan proses binerisasi yaitu im2bw. Contoh penerapan pada MATLAB:

$\mathrm{I} 3=\mathrm{im} 2 \mathrm{bw}(\mathrm{I} 3)$;

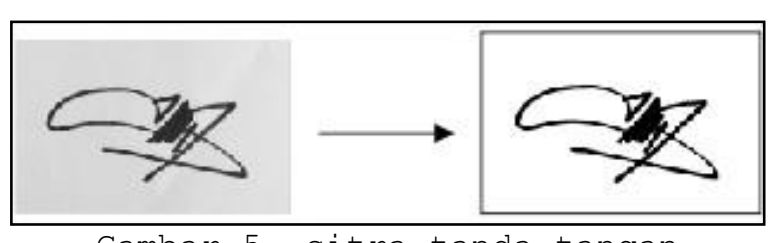

Gambar 5. citra tanda tangan

\section{Tahap Thining}

Thinning adalah operasi morfologi yang digunakan untuk mengikis piksel latar depan sampai menjadi pixel yang tipis. Proses thining membuat garis pada citra menjadi 1 pixel. MATLAB menyediakan fungsi untuk melakukan proses thining yaitu bwmorph('thin', inf). Contoh penerapan thining pada MATLAB

$\mathrm{I} 3=\operatorname{bwmorph}(\sim \mathrm{I} 3$, 'thin', inf $)$;

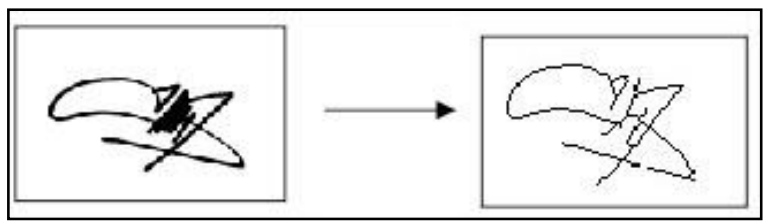

Gambar 6. citra tanda tangan

\section{Tahap cropping}

Cropping adalah memotong satu bagian dari citra sehingga memperoleh citra yang berukuran lebih kecil. Cropping juga berarti pemotongan dari bagian image untuk meningkatkan konsentrasi gambar yang diutamakan.

$X^{\prime}=X-X_{L}$, untuk $X=X_{L}$ sampai $X_{R}$

$\mathrm{Y}^{`}=\mathrm{Y}-\mathrm{Y}_{\mathrm{T}}$, untuk $\mathrm{Y}=\mathrm{Y}_{\mathrm{T}}$ sampai $\mathrm{Y}_{\mathrm{B}}$

Keterangan:

$\mathrm{X}_{\mathrm{L}=\text { nilai sisi kiri }}$ 
$\mathrm{X}_{\mathrm{R}=\text { nilai sisi kanan }}$

$\mathrm{Y}_{\mathrm{T}}=$ nilai sisi atas

$\mathrm{Y}_{\mathrm{B}}=$ nilai sisi bawah

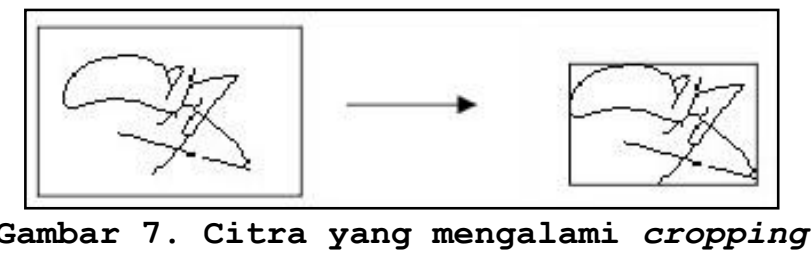

\section{Tahap ekstraksi ciri dengan edge detection}

Edge detection merupakan langkah pertama untuk melingkupi informasi didalam citra. Tepi berguna untuk segmentasi dan identifikasi objek di dalam citra. Pada aplikasi verifikasi tanda tangan digunakan deteksi tepi dengan operator gradien pertama yaitu operator prewitt. Metode Prewitt merupakan pengembangan metode robert dengan menggunakan filter PF yang diberi satu angka nol penyangga. Metode ini mengambil prinsip dari fungsi laplacian

MATLAB menyediakan fungsi untuk melakukan proses prewitt yaitu edge('prewitt').Contoh penerapan thining pada MATLAB.

PR = edge(im,'prewitt');

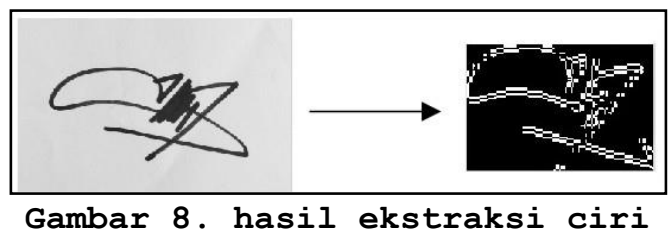

Hasil dari ekstrkasi ciri berupa nilai vektor yang akan disimpan ke dalam basis data tanda tangan, dimana akan digunakan pada proses pencocokan.

Tahapan proses pengujian memiliki langkah tahapan yang sama dengan proses pelatihan sampai dari mulai proses resize sampai dengan tahap ekstraksi ciri. Pada tahap pengujian terdapat tahapan pencocokan data dengan data latih yang sudah tersedia di basis data. Tahap verifikasi menggunakan metode LVQ (Learning Vector Quantization)

\section{Tahap Verifikasi dengan LVQ}

Data latih ketika gambar data uji yang telah ditemukannya vektor dari hasil deteksi tepi maka diverifikasi dengan LVQ untuk mengklasifikasiakn bobotnya dengan yang ada didalam data latih. Bobot citra uji yang mendekati bobot target, maka menyatakan sebagai asli atau cocok. jika bobotnya terlalu jauh dengan bobot target maka dinyatakan palsu / tidak cocok. Metode LVQ ini hanya mencari bobot terkecil dari data uji.

Contoh kasus saat pengujian dengan LVQ sebgai berikut. Terdapat sebuat tanda tangan. Tanda tangan yang dibuat $3 \times 3$ pixel bertujuan untuk mengetahui pixel mana saja yang mengenai garis tanda tangan. Pixel yang mengnai garis tanda tangan diberi nilai 1 dan yang tidak mengenai garis tanda tangan diberi garis 0 .

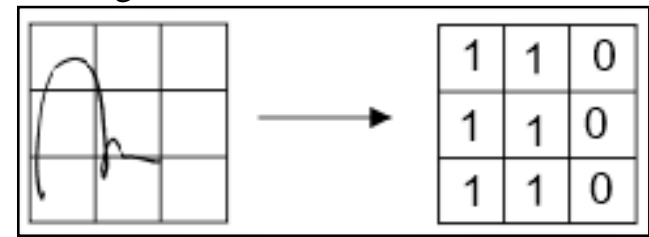

Gambar 9. tanda tangan dalam bentuk matriks

Didapat vektor dari data uji $(1,1,0,1,1,0,1,1,0)$. dan di hitung bobot terendah dari data latih. Rumus untuk memperbarui bobot sebagai berikut 


$$
\vec{W}_{m} \leftarrow \vec{W}_{m}+\eta \cdot\left(\vec{X}-\vec{W}_{m}\right)
$$

Keterangan:

$\vec{W}_{m}=$ bobot

$\mathrm{n} \quad=$ Learning rate

$\mathrm{X}=$ masukan

$\vec{W}_{m \text { (baru) sama dengan }} \vec{W}_{m}$ lama ditambah n yang merupakan learning rate yang dikali dengan hasil dari masukan dikurangi $\vec{W}_{m}$ lama.

Data latih berupa bobot w1 dan w2 karena ada 2 kelas. w1 untuk kelas 1 dan w2 untuk kelas 2 dengan bobot vektor akhir $\mathrm{W}_{1}=(1,0.9901,0,1,1,0.9902,1,0.0099,0.0099)$ dan $\mathrm{W}_{2}=(0,1,1,0,1,1$, $0.0099,1,0)$. Berikutnya menghitung bobot terdekat dengan menguji data uji dengan mencari bobot terdekat dari data latih, dapat dilakukan sebagai berikut.

Jarak pada bobot ke $-1=$

$(1,0.9901,0,1,1,0.9902,1,0.0099,0.0099)$

$=\left((1-1)^{2}+(1-0.9901)^{2}+(0-0)^{2}+(1-1)^{2}+(1-1)^{2}+(0-0.9902)^{2}+(1\right.$

$\left.-1)^{2}+(1-0.0099)^{2}+(0-0.0099)^{2}\right)^{1 / 2}=1.40$

Jarak Pada bobot ke - $2=(0,1,1,0,1,1,0.0099,1,0)$

$=\left((1-0)^{2}+(1-1)^{2}+(0-1)^{2}+(1-0)^{2}+(1-1)^{2}+(0-1)^{2}+(1-0.01)^{2}+(\right.$

$\left.1-1)^{2}+(0-0)^{2}\right)^{1 / 2}=2.23$

Dari hasil perhitungan kedua bobot, bobot ke-1 yang memiliki nilai terkecil. Maka hasil data uji tersebut masuk ke kelas 1 karena data uji mendekati bobot ke-1.

\subsection{Implementasi dan Pengujian Sistem}

Setelah melakukan analisis dan perancangan tahap berikutnya adalah implementasi dan pengujian. Pada tahap implementasi dilakukan implementasi desain antarmuka

\subsubsection{Implementasi Sistem}

\section{Menu Verifikasi}

Menu verifikasi merupakan menu utama dari aplikasi verifikasi tanda tangan. Pada menu ini terdapat 4 tombol, 2 kotak tulisan, dan 1 axes untuk menampilkan gambar, yang ditampilkan pada Gambar.10.

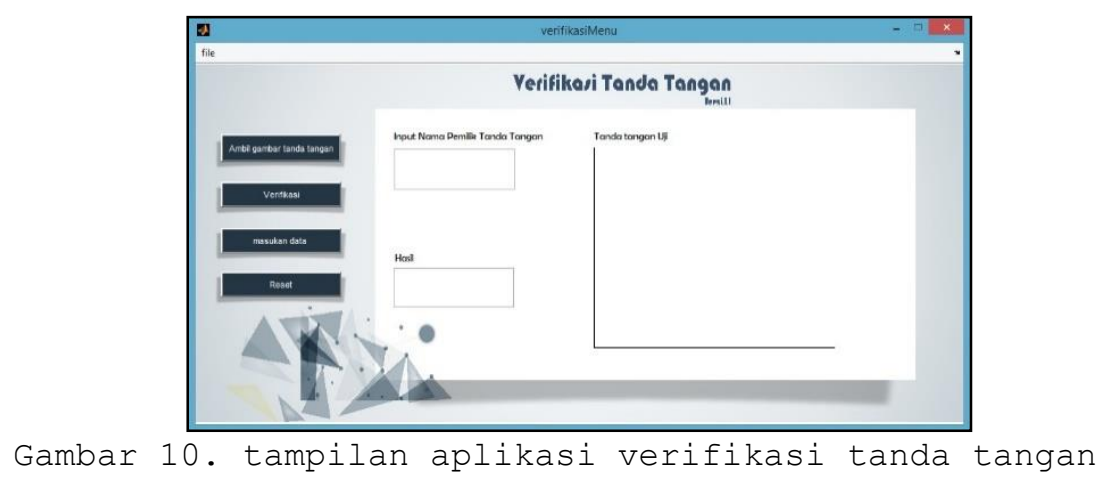

Menu verifikasi dapat langsung memverifikasi sebuah tanda tangan. bila sudah ada data latih yang disimpan dengan mengambil tanda citra tanda tangan lalu jika tanda tangan sudah tampil maka isi pada kolom masukan nama pemilik tanda tangan sebai pemilik tanda tangan tersebut.. Terdapat contoh verifkasi yang ditampilkan pada Gambar.11. 


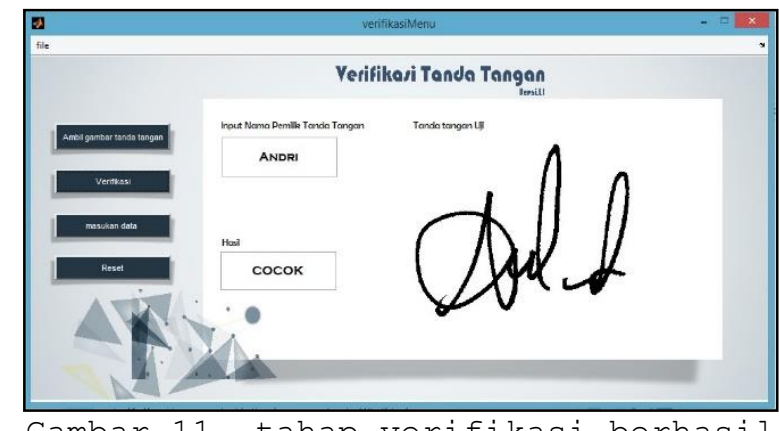

Gambar 11. tahap verifikasi berhasil

percobaan dilakukan dengan tanda tangan palsu. Dengan tanda tangan orang yang sama seperti pada Gambar 7, tetapi dibuat oleh orang yang berbeda maka didapat hasil seperti pada Gambar.12.

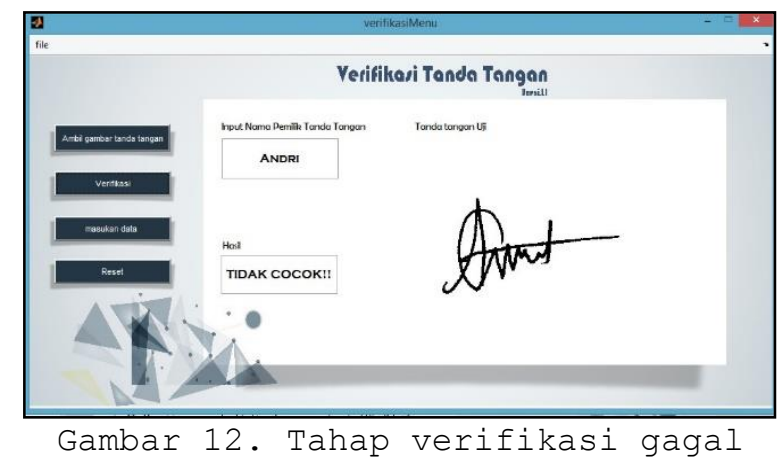

Terjadi ketidak cocokan dengan nama dan citra gambar, maka aplikasi akan mendeteksi bahwa tanda tangan tersebut palsu.

\subsubsection{Pengujian Sistem}

Pengujian dilakukan oleh 10 orang yang berbeda dan terdiri dari 30 tanda tangan setiap orangnya untuk dijadikan data latih dan 100 tanda tangan asli sebagai data uji pada Tabel 1.

Tabel 1 pengujian tanda tangan asli

\begin{tabular}{|c|c|c|c|}
\hline No & Nama & Jumlah citra uji & hasil kecocokan \\
\hline 1 & P1 & 10 & 10 \\
\hline 2 & P2 & 10 & 10 \\
\hline 3 & P3 & 10 & 10 \\
\hline 4 & P4 & 10 & 10 \\
\hline 5 & P5 & 10 & 10 \\
\hline 6 & P6 & 10 & 0 \\
\hline 7 & P7 & 10 & 10 \\
\hline 8 & P8 & 10 & 0 \\
\hline 9 & P9 & 10 & 10 \\
\hline 10 & P10 & 10 & 0 \\
\hline
\end{tabular}

Tingkat kesuksesan (\%) untuk 10 orang dan 10 citra tanda tangan

$$
\frac{\text { hasil yang mendapat kecocokan }}{\text { Total jumlah citra data uji }} \times 100
$$




$$
=\frac{70}{100} \times 100=70 \%
$$

Percobaan dilakukan juga dengan tanda tangan palsu yang dibuat. Dari hasil 100 tanda tangan palsu masih terdapat kesalahan. bisa di lihat pada Tabel.2.

Dari hasil pengujian tanda tangan palsu. untuk tanda tangan koresponden 4 dan koresponden 5 yang di palsukan terdapat 3 tanda tangan yang terverifikasi. untuk tanda tangan Koresponden 9 yang di palsukan terdapat 4 tanda tangan yang terverifikasi. Untuk tanda tangan koresponden 2 dan koresponden 7 yang dipalsukan, terdapat 5 tanda tangan yang terverifikasi. untuk tanda tangan koresponden yang di palsukan terdapat 10 tanda tangan yang terverifikasi. Dan untuk koresponden 1 , koresponden 6 , koresponden 8 dan koresponden 10 tidak ada tanda tangan yang terverifikasi satupun.

Tabel. 2 pengujian tanda tangan palsu

\begin{tabular}{|c|c|c|}
\hline No & Nama & Hasil Kecocoka tanda tangan \\
\hline 1 & P1 & 0 dari 10 tanda tangan palsu \\
\hline 2 & P2 & 5 dari 10 tanda tangan palsu \\
\hline 3 & P3 & 10 dari 10 tanda tangan palsu \\
\hline 4 & P4 & 3 dari 10 tanda tangan palsu \\
\hline 5 & P5 & 3 dari 10 tanda tangan palsu \\
\hline 6 & P6 & 0 dari 10 tanda tangan palsu \\
\hline 7 & P7 & 5 dari 10 tanda tangan palsu \\
\hline 8 & P8 & 0 dari 10 tanda tangan palsu \\
\hline 9 & P9 & 4 dari 10 tanda tangan palsu \\
\hline 10 & P10 & 0 dari 10 tanda tangan palsu \\
\hline
\end{tabular}

Pada pengujian tanda tangan palsu tingkat keberhasilan mencapai $=\frac{30}{100} \times 100=30 \%$

\section{KESIMPULAN}

Berdasarkan hasil penelitian yang diperoleh dari pengujian sistem yang menerapkan metode edge detection dan metode Learning vector Quantization, diperoleh kesimpulan bahwa Metode Learning Vector Quantization dapat mengenali pola tanda tangan dengan Tingkat akurasi untuk proses verifikasi mencapai $70 \%$ untuk mengenali tanda tangan asli.

\section{DAFTAR RUJUKAN}

[1] Kusumadewi, S. 2003, Artificial Intellegence (Teknik dan Aplikasinya), Graha Ilmu, Yogyakarta

[2]Kasus pemalsuan tanda tangan (http://surabaya.tribunnews.com/2015/08/02/kasuspemalsuan-tanda-tangan-tahun)

[3]Muntasa arif , 2010, Konsep pengolahan citra digital dan ekstraksi fitur, Graha Ilmu, Yogyakarta

[4]Putra Darma, 2009.Sistem Biometrika Konsep Dasar, Teknis analisis Citra, dan Tahapan Membangun aplikasi sistem Biometrika

[5]Santosa Budi, 2007, Data Mining Terapan dengan Matlab, Graha Ilmu, Yogyakarta. 